\title{
SOME ISSUES CONCERNING THE ELEMENTS OF CONTROL FUNCTION OF MANAGEMENT
}

\author{
Sorin Domnişoru ${ }^{l}$ \\ Oana Gherghinescu ${ }^{2}$ \\ Radu Ogarca ${ }^{3}$
}

\begin{abstract}
In the field literature and the specific practice, the use of terms, such as - control, verification, evaluation, audit, on one side, and on the other side, the definitions for control function of management, respectively, control-evaluation function - remain highly ambiguous. Considering these observations, the authors point out several useful aspects meant to clarify this issue. In order to highlight the complexity and the integrality of the management function, the analysis of the elements composing a control system is undertaken. Constantly, the parts are reported to the whole; therefore, those concerning the evaluation and the verification are reported to the system providing the exercise of the control function. Willing to eliminate ambiguity, for each of the concepts involved, certain substances are proposed, as being considered better confined and oriented.
\end{abstract}

Keywords: management, control, verification, evaluation, audit

JEL codes: $M$ 10, $M 42$

\section{Introduction}

"If anything can go wrong, it will go wrong" is one of the Murphy's pessimist laws, warning the managers to stay focused on eventual issues, because, even if a system seems to perform standardly, it may be undermined slowly inside/from inside. Therefore, in order to avoid the abnormal functioning within an organization, the management develops a system which provides insurances concerning the concept of dominance/direction, a possible alternative for control function. However, one may notice that for the field language, as well as for legal regulations indicating the same topic, concepts, such as, control, audit and verification are easily used. Thus, we have expressed certain opinions related to this triad and to the content of the control function of management.

\section{Research Methodology}

Our approach aims at presenting a personal interpretation of the orientation, place and role of verification, evaluation and internal audit within the control function of management and against the existing economic and social background, as well as the differences between control and control-evaluation functions.

The approach provides a synthesis and an antithesis of the ideas deriving from this topic, proposed by the field literature, of the regulations elaborated by different national and international organisms. Therefore, we appreciate the fact that a proper use of the concepts and a professional expression will ease our task.

For achieving our objectives, we have applied a constructive methodology for determining the criteria, for supporting and elaborating a discourse, for pro-reconsideration of national regulations of the area and their harmonization with theory and practice within developed countries.

\footnotetext{
${ }^{1}$ University of Craiova

${ }^{2}$ University of Craiova

${ }^{3}$ University of Craiova
} 


\section{What is Control?}

The economic literature proposes numerous ways of considering the concept of control (taking into account its mechanisms, role and objectives), classified on branches of economic science from which derive - management, finances, accountancy, audit, etc. We shall provide a brief review of several of these approaches, emphasizing the fact that, obviously, the concept of control is not an exclusively economic category.

For the beginning, we assume that certain specifications and semantic constraints are needed. Therefore, according to DEX (1998) the concept of control represents "permanent or periodic analysis of an activity meant to provide improvement measures", but also "continuous supervision (moral or material); dominance". Given this definition, as other terms are employed, we should precisely indicate their meaning, too:

- Analysis - study of the whole, of a phenomenon, examining each constituent;

- Verification - action of searching for the truth, for reality, and whether everything occurs in conformity with the standards or certain specifications;

- Dominance (for the sense given in control definition) - a good knowledge of the business line - as well as the action of blocking somebody's actions or of restraining somebody from doing something; to hold back, to rein in.

Synthesizing and concentrating ourselves over the concept of control as a function of the management, over its procedural nature, we may introduce a dimension of analysis, a dimension of verification (an extra element as compared to the analysis, meeting pre-determined standards), indicating an initiation of corrective actions and, a reflection of the evolution of the economic world, as well as a dimension of "dominance" of contexts, particularly, internal (but also external) to the organization.

The economic literature develops, more or less, between these coordinates. To this respect, H. Fayol defines the concept of control as "an action of checking whether everything is being carried out in accordance with the adopted plan, with orders which have been given and with the principles which have been laid down" (in Boboc, 2003). According to Fayol, the object of control consists in detecting weaknesses and errors, their correction in due time and prevention of improper action recurrence.

A.N. Tannenbaum (1968) defines the concept of control as a "process in which a person or group or organization determines or intentionally affects what another person, group or organization will do"3.

R. Mockler (in a paper dated in 1970) considers control as "a systematic effort made by business management to compare performance to predetermined standards and to undertake, if necessary, corrective actions to see that human and other corporate resources are being used in the most effective and efficient way possible in achieving business objectives." (Certo, 2002, p. 557)

According to E. McKenna (in a paper dated in 1988), the concept of control may be seen as "the minimization of idiosyncratic behavior and the promotion of conformity in accordance with explicit plans" (in Morris et al). Slightly following the same idea, A. Burlaud and C.J.Simon (1997) defined control as "a system of adjusting behaviors" as well as "a language with a strong influence on those who use it, because a language represents in itself a vision of the world and those who speak it are forced to adopt it". Through its characteristics, control may be seen as a way of unifying concerns and behaviors, fact which has greater importance when dealing with larger groups, more varied and geographically spread out. Language gives shape to reasoning. For example, the finance language introduced within an organization (words, as well as indices stand for standards) requires more interest than financial concerns.

A. N. Anthony (1995) defines control as "a process by which managers ensure that resources are produced and used effectively and efficiently for achieving the goals of the organization". 
According to Adam Jr. and Ebert (2001, p. 437) who propose a more general vision, control is a process through which a characteristic of the system is transformed in order to generate the desired change meant to improve the system.

According to a source of reference specific to the area dealt with, a control system is made up of policies and procedures meant to provide the management a reasonable guaranty, namely, that the entity achieves its predetermined goals. These policies and procedures are often defined as control mechanisms and represent, on the whole, a basis providing control to managers and shareholders inside and over the entity (Arens et al., 2006, p. 332).

According to Nicolescu and Verboncu (2001, p. 27), "control represents the entire body of processes measuring and directing performances, subsystems and components of the organization against predetermined plans and goals in order to eliminate detected deficiencies and to integrate positive deviations".

Considering the national legislation, the concept of control implies:

- All the principles, criteria, norms and methods concerning the organization inside the entity, including the mood or the specific strictness;

- All internal procedures, among which we mention: purchase procedure, registration procedure, claim monitoring and recovery procedure etc.

- Preventive financial control;

- Other forms of internal control, with no specification in the law (OG 119/1999) meant to clarify which are these forms. Considering the size, the profile and the policy of the organization, there different forms of control: task separation to avoid incompatibilities, technical and quality control of generated products and services; hierarchical control correlated to accounting control and verifications, management financial control; labour protection control; trade control, sanitary control etc.

As a preliminary corollary, we may state that the concept of control does not define only actions, mechanisms, procedures, but also a "philosophy" developed within the organization which allows the activity evolution in accordance with stakeholders' plans, purposes, and expectations. Moreover, the difference between internal and external control looses its importance, no matter whether we relate to rights and responsibilities of a part of stakeholders (from inside) or to social responsibility of the organization and its sustainable evolution.

\section{Objectives and Characteristics of Control}

In our opinion, the concept of control is richer in content than that of verification-evaluation, and includes, among its objectives, the goals achievement to an adequate level within the organization, as well as the development and maintenance of certain system of collecting, stocking, processing, updating and transmission of financial and management data and information. Control mechanisms applied within the organization are meant to encourage the efficient and effective utilization of its resources, including human resources, for the purpose of optimizing the company actions. An important part of the results registered by these control mechanisms provides correct information intended for the internal decision-making process.

Another crucial component of the dominance system is that of protecting the assets, including the inventory of the organization.

At the same time, the control system is aiming at abiding the enforced laws and regulations. Entities have the obligation to abide numerous laws and regulations. Most of these governmental decrees are only partially related to accountancy. As the control system tends to develop, beyond these aspects which directly concern the accounting and financial-accounting and control system within the entity, there is great influence over the management and control covers the first line of defense in protecting the wealth against eventual losses and in enhancing the achieved performances. 
All these considerations lead us to a certain substantial viewpoint - control should not be considered as a purpose in itself, but as a way of achieving a goal, namely, the improved functioning of the system within the organization (Adam, Ebert, 2001, p. 437), including its formation in order to face the changes occurring outward (Dalotă, 2003, p. 298).

In theory, as well as in practice, we may identify a series of characteristics of control. Briefly, we shall feature the most significant ones:

Control represents a continuous integration and incorporation on the operations. Control is not a very precisely delimited event or, in other words, it is not confined to verification, on the contrary, it consists of a series of means and processes, of actions developed simultaneously with the entity operations, in a continuous manner. It should exist as an integrant part of each system applied by the management for the regulation and coordination of all the initiated and developed operations, without being viewed as a distinct unit of the entity. Control is achieved as part of the philosophy, architecture and logistics of the organization supporting managers in leading the entity, in this manner, all planed objectives would be completed.

Management has the charge of an adequate control meant to set its objectives, to apply its mechanisms, to monitor and evaluate it. Beside available technical and financial means, control is an essential instrument used and created by the management for fulfilling the goals of the organization. As for all efforts exerted by the organization, control actions should be undertaken only if benefits deriving from this kind of activities exceed the costs required for their development. In many cases, management is not ready to introduce a system which tends to be ideal due to the fact that costs could be very high and there might be collateral losses.

For example, a company counting 7 employees and numerous business sites has as a main line of business renting locations to third parties with the view of selling varied merchandises within these sites. Renting contracts included the following claim: the third party owes the lessor $3 \%$ of the turnover registered for the rented location, but not less than 1000 euro/month.

The economist took notice of the fact that all the 60 clients actually owed monthly 1000 euro, as the stated turnover was too small to consider the application of the $3 \%$ to gained returns. Moreover, because of the high price of the rent, as compared to the potential of certain companies, the occupancy rate of rented spaces indicated $70-75 \%$.

The same economist or, in other words, a part of the internal control system, considered the following mechanisms of optimizing the business:

- In order to monitor the sales, clients were asked to present copies for the reports printed by the cash registers, an irrelevant mechanism because these reports corresponded to the stated turnover for those respective locations.

- To place an employee inside each location rented, charged with monitoring the sales. The procedure proved to be very expensive; the efforts for keeping 60 extra employees, together with the depreciation of assets, largely exceeded possible revenues.

- To place personnel to the exit way of each site; the personnel being charged with monitoring the sales achieved by each partner considering fiscal receipts. The system risked generating, physically, a strangulation of the business circuit, or psychologically, to affect the business fund allotted to those locations. The conclusion was that this mechanism of internal control, too, was inappropriate.

- To connect cameras in each location. Technically, this measure did not provide an adequate monitoring of sales achieved by business partners and, besides, it was highly expensive....

Finally, another system of pricing was adopted and applied by the company during its collaboration with the clients. Prices were established, exclusively, as absolute sums differentiated according to the nature of merchandises and the positioning of different areas inside the site - for food products 20 euro/month $/ \mathrm{m}^{2}$; cosmetics and mobile services $50 \mathrm{euro} / \mathrm{month} / \mathrm{m}^{2}$; for clothing, knits and other garments 40 euro $/ \mathrm{month} / \mathrm{m}^{2}$ in season and 10 euro $/ \mathrm{month} / \mathrm{m}^{2}$ in extra season; for coffee, cigarettes and alcoholic beverage 60 euro $/ \mathrm{month} / \mathrm{m}^{2}$ etc. 
In this manner, monitoring the partners' sales was no longer necessary for the management, the company achieving a $40 \%$ increase in revenues and an occupancy rate of $90-100 \%$ in renting the locations to different clients.

Analyzing this example, a control component has identified at least two risks which were avoided by recommending the change of renting contracts conclude with the clients. In other words, a mechanism of control was created providing a reasonable guaranty for the company in achieving its goals.

Inherent restrictions. Mechanisms of the internal control could never be considered as perfect means, regardless of their design and application. For example, even if an ideal system was conceived, its efficiency would depend on its users' ability and reliability. The concept of control should not be generalized or idealized; this tendency is perceived in the practice of some organizations, and also in the field literature. For example, the English professor Charles Lane claims that control function is the only important function of management (Nicolescu, Verboncu, 2001, p. 27).

Rabindranath Tagore, Indian philosopher wrote down in a metaphorical manner: „If you shut the door to all errors, truth will be shut out" (in Russu, 1999, p. 317). Returning to present and to scientific literature, it is obvious that for many managers to avoid failure seems to be more important than having success. This seems to be connected to their experience revealing the fact that most of the managerial systems largely punish the failure, than rewarding the success, and whereas the burden of a failure remains attached to an individual, as a hall-mark, the news of a success vanishes in an instant, similar to a volatile substance (Görg, 1997, p. 63).

Following the same idea Peter Drucker, a guru of the management, mentioned that: „The better a man is the more mistakes he will make - for the more things he will try. I would never promote into a top level job who had not made mistakes, and big ones at that. Otherwise he is sure to be mediocre" (in Beatty, 1998, p. 86).

This reasoning leads us to the idea that control has to be an interactive function, too. This approach has been introduced by Robert Simons (1995). The interactive control defines the "attention" (wakefulness) of the management to all evolutions - negative evolutions, as well as positive ones - influencing the organization and demanding new strategic initiatives. As a graphical representation of this approach, we propose the following chart:

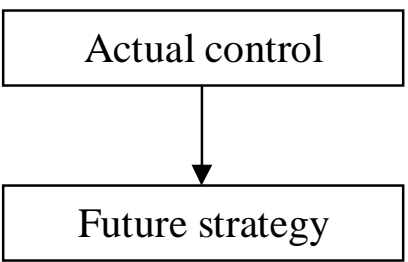

Fig. no. 1 - Interactive character of control Source: Anthony (2001)

To this effect, Stevenson and Jarillo (1996) discuss about a comparison between the traditional approaches "order and control" and the new approach "early warning". Control should become an instrument applied for managing incertitude, promoting risk assumption, encouraging certain initiatives and forcing employees to assume responsibilities (H. Oden, 1997, in Morris et al.). According to this new orientation, the control system has a key role in risk management, a significant determining factor in achieving organizational objectives (Turnbull, Internal Control Working Party, 1991, p. 4). Thus, managers have the opportunity of developing control systems able to consider, besides financial aspects, a range of risks to which the organization is exposed (Spira, op. cit.). 


\section{Elements of a Control System}

Generally, we may affirm that a control system, within an organization, comprises five categories of elements: medium of control; risk management; control, information and communication activities, and supervision. Each category may be well supported by arguments and includes numerous elements of control that we shall briefly describe.

i. Medium of Control. The medium of control detaches as a real pillar of internal control system, its task being to protect, constrain and determine the other components of control. Lacking of an adequate medium of control, it is slightly probably that the other four components could lead to an efficient control, regardless of their quality.

Following the analysis of the medium of control, we have noticed that it includes actions, policies and procedures which reflect general attitudes assumed by the management, the board members and/or by the owners of the organization towards control and its important role within the organization. The medium of control, particularly, as well as the control system are influenced by a series of factors: organizational culture, organizing structure, informational system, human resources management, management style. These influences may be graphically influenced as in figure below:

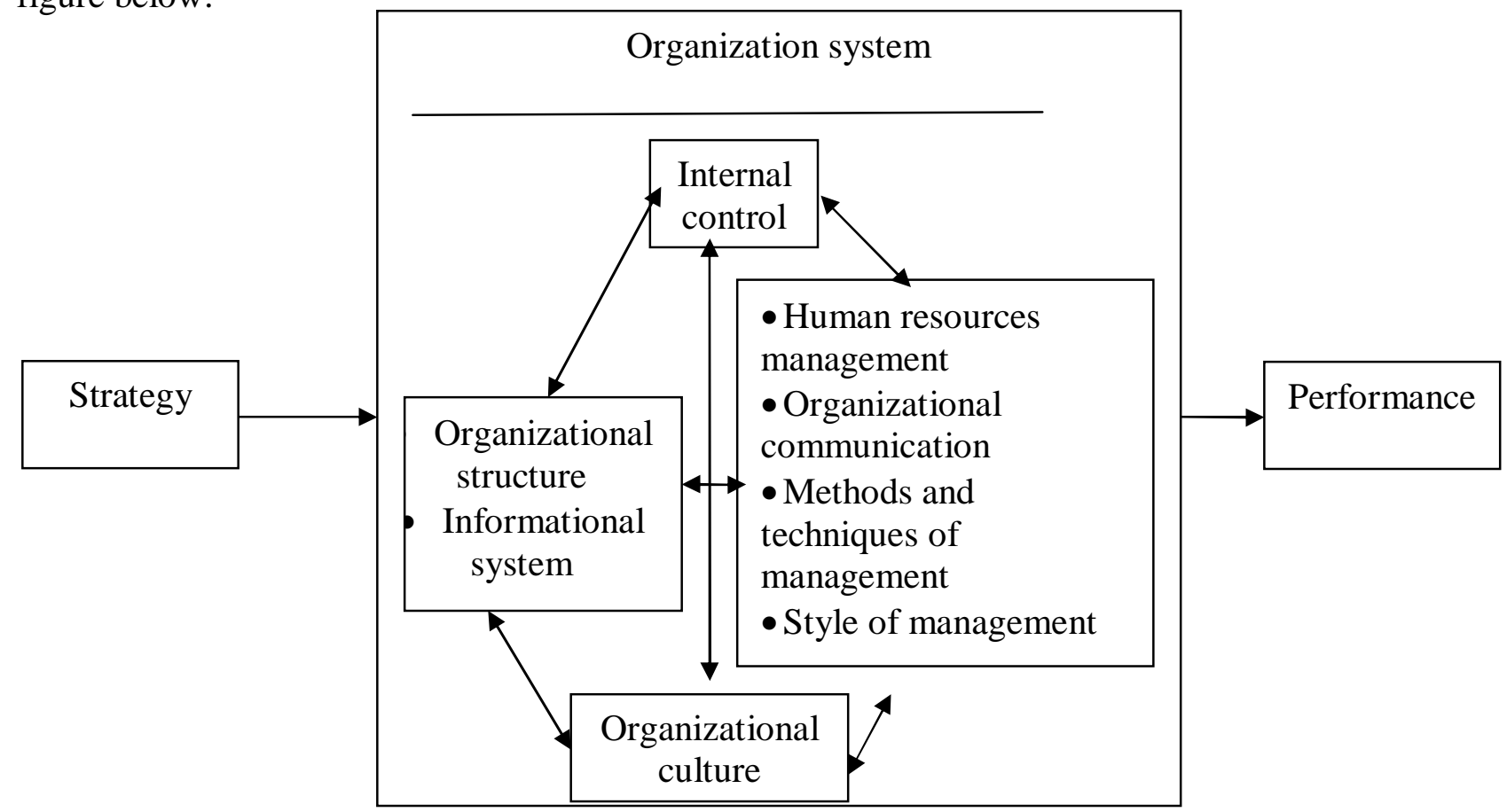

Fig. no. 2 - Determining factors of control system of the organization Adaptation after: Anthony, 2001, p. 8

We shall continue to synthetically present the most important mutual influences.

The organizational culture is seen by Edgar Schein as "a pattern of basic assumptions for learning, discovered or developed by a certain group, a certain collectivity, during the process of learning how to successfully solve the issues related to the external evolution and internal integration, which has registered an adequate development for a certain period of time, in order to be validated, and which is going to be transmitted to the new members as an optimum way of perceiving, thinking and feeling connected to those issues" (Năstase, 2004, pp. 29-30).

Ov. Nicolescu (2001) considers the organizational culture as "the aggregate of values, faiths, aspirations, expectations and behaviors designed in time within each organization, having a dominant status within it and directly and indirectly determining its functioning and performances". 
The organizational culture is a major factor determining members' behavior within an organization; it may influence the level of achieving the goals and the tasks developed by the organization through directing the employees' potential and grafting certain behaviors and adequate attitudes able to trigger employees' latent energies and, likewise, able to provide the conservation of the organizational excellence, representing the needed support in adopting the best solutions and the most suitable behaviors meant to face the hostilities of the medium (Stanciu, Ionescu, 2005, p. 57). Connected to the elements of control, the organizational culture foresees a set of common frameworks learned during social interactions, forwarded heart-to-heart and, at the same time, having a rule-making nature. In other words, the organizational culture helps the employees to understand what they are allowed to do and what they are not, as long as they are at work (De Vries, 2003, p. 233). The organizational culture may provide reliability, if it is based on autonomy and openness to ideas, or fear and reprisal. For the first case, we may observe the prevalence of informal and discipline control measures, for the other case, formal control systems, as an imposition coming from outside (Ionescu, Cazan, 2004, p. 283).

Among the elements of the organizational culture, a significant role in configuring the control system is played by the system of values and, respectively, behavioral norms.

Values represent "the essence of the culture", the essence of the success philosophy implemented by the organization, the central element which gives a sense to a common direction and indicates the way in which the members of the organization should work together (Huţu, 2003, p. 100). When the organizational culture gains strength, values will absorb general attention; otherwise, values would be ignored. When dealing with strong cultures, values play the role of an informal control system which grows stronger than any other control system, due to the fact that it provides purpose and significance for everything that is meant to be achieved for performance (Huțu, 2003).

Behavioral norms consist of habits, traditions, rituals and ceremonies under the title of (un)written rules of the organization (Stanciu, Ionescu, 2005, p. 46). Norms should be formal concerned with official and organizational regulations (functioning rules, of interior order, specifications of functions, positions, decisions) or informal (orally transmitted as examples, having great influence on employees).

Informal norms, values and faiths implemented within the organizations also establish the tone of moral reasoning within the company (Ionescu, 2005, p. 628), determining the removal and the diminution of motivations or temptations which might engender the employees to get involved in unfair, illicit, immoral deeds, or the contrary.

In order to get values and norms known and respected by the employees of a company, it is essential that, between whiles, during the operating life of the organization, an introduction and explicit details of major values, meant to guide the decisions and the actions of the personnel concerning internal and external interactions of the company, to be set forth.

Values and organizational norms communication reproduces a continuous process, manifested under formal, as well as informal, explicit and implicit aspects (Năstase, 2004, p. 75).

As an important component and resource inside the organizational culture, the managerial culture is developed. This concept refers to the system of managerial values, faiths, aspirations, expectations and behaviors which is reflected in the management styles and types applied within the organization, indicating, in an obvious manner, the content of the organizational culture and the company performances (Stanciu, Ionescu, 2005, p. 79). We outline this consideration by means of emphasizing the fact that, by many of the managerial culture dimensions, the management attitude, the management working philosophy and style and the commitment for competence (see Arens, 2006, pp. 334-336) develop a significant influence on the control system.

We should also mention that all these elements of the managerial culture register a determiner in the concept of manager's temper. This concept, beside the influence mediated through the organizational and managerial culture, may also influence, in a direct way, the design of 
the control process within an organization. The table below synthetically illustrates these possible connections:

Table no. 1

\section{Correlation between manager's temper and the type of control employed}

\begin{tabular}{|l|l|}
\hline \multicolumn{1}{|c|}{ Temper } & \multicolumn{1}{c|}{ Type of control } \\
\hline Cheerful & Active control, diplomatic, pleasant, efficient \\
\hline Choleric & Active control, tending to anger \\
\hline Stolid & Efficient control, slightly tending to "nagging" \\
\hline Wistful & Tendency toward tolerance \\
\hline \multicolumn{2}{|c|}{ Source: Boboc, 2003, p. 111}
\end{tabular}

The organizing structure of an entity represents the group of individuals and organizing subunits constituted and interconnected to provide organizing premises meant to establish and achieve foreseen objectives (Nicolescu, 2003, p. 30). By understanding the organizing structure, the managerial and functional aspects of an economic entity are better perceived, as well as the way in which control mechanisms are applied, therefore, a biunivocal strong correlation is established between organization and the concept of control.

During the last century, the pyramid constituted the organizing symbol of control, status and bureaucracy. Recently, organizing symbols oriented towards networks and "cobwebs", having as distinctive marks operational or ad-hoc teams, unconfined and chaotic horizontal processes or virtual systems (Ulrich, 2002, p. 144).

The hierarchy has been set for conserving a series of valuable capacities: precise responsibility, legitimate authority, predetermined routines, work division and professional background. In a world of unforeseen changes, of globalization, of dynamic technologies, of educated employees and clients, these capacities will no longer yield favorable results.

The employees of the future organization will prove autonomy, self orientation and self motivation. This way of performing is enforced when the employees are aware of the expectations of the company, of its orientation and of the reason for this orientation and of the individual contribution to the achievement of the general goal. The results of this new way of perceiving things will be materialized at low costs due to a reduced need for supervision and to a better quality relying on more competent decisions (Hesselbein et. al., 2002, p. 146).

Human resource policies and practices. The most important aspect of control within an entity is the personnel operating here. When dealing with competent and reliable employees, even in the absence of other types of control mechanism, there is competitive activity within the organization. Honest and efficient individuals are able to perform a high quality-related work even if there are few types of control mechanisms. Contrarily, even if numerous other control mechanisms are applied, incompetent or unreliable individuals may transform the system into a real chaos. Despite the existence of a competent and reliable personnel, it is wrong to disregard the fact that people possess a series of innate weaknesses (although most of the specialists in management consider X Theory as being obsolete). For example, they may get bored or become unsatisfied; their personal issues may affect professional performances or their planned objectives may change.

Taking into account the important role of competent and reliable personnel in providing an adequate control, all methods applied for hiring, evaluating, training, promoting and rewarding the individuals represent a crucial aspect of any managerial control system; these considerations are far away from the meaning of verification, but they imply a highly useful activity in providing control.

ii. Risk Evaluation and Administration by the Management of the Entity. All the organizations, regardless of their size, structure, designation, nature or industry, are facing different risks deriving from internal or external sources, which must be managed. Considering the fact that economic, industry, juridical and operational circumstances evolve, management should respond to 
the challenge of creating useful mechanisms meant to identify and to administrate the risks associated to these changes. Control, suiting a single set of circumstances, will no longer be efficient, will no longer adapt if these circumstances evolve. Therefore, control should be focused on an important aspect of activities, that of internally and externally scanning the medium of the organization.

The identification and analysis of risks represent a continuous process and a critical component of an efficient control. Management should be focused on risks to all levels of the organization and undertake all necessary measures to eliminate these risks. Following risk identification, management needs to estimate its importance, to evaluate the probability of its occurrence and to formulate specific measures meant to reduce the risk to an acceptable level.

iii. Activities of control represent a series of policies and procedures, beside those included by the others components, providing the fact that for achieving their goals, entities adopt necessary measures in order to face the risks affecting their activity. By their definition, there are five types of activities of control: adequate separation of responsibilities; adequate commission of operations and activities; adequate elaboration and registration of documents; independent verifications of norms application and of results achievement. We shall not insist on analytical aspects concerning these activities, our main focus being the last activity of control.

Therefore, the independent verification of norms application and of results achievement consists in a comparative, rigorous and anonymous examination of the other four categories. One may notice the need for independent verifications determined by the fact that control tends to get "used" in time, in the absence of a mechanism of periodical verification. This category of verifications includes at least: preventive financial control, financial and accounting verificationreview and administration control, quality control etc. It is possible that employees forget to apply a norm, or they deliberately refuse to apply a procedure or they become careless if nobody verifies them. In addition to these situations, no matter how competitive are the mechanisms of control, their might exist accidental/planned errors.

From the perspective of verifications or of control, we may state that the applied indices and the criteria drawn upon represent an impulse towards performance. An optimum system of evaluation, as an integrant part, leads the organization in a positive direction. a system incorrectly conceived and applied, on the contrary, may be damaging (Harrington, Harrington, 2000, p. 349).

Expert managers are hired only for protecting stakeholders' investments, as well as for conferring them value. Performance indices fulfill both functions: they indicate whether the company is under short-term control and whether value is generated for long-term. It often happens that the objective of the short-term control prevails over the objective of generating value for stakeholders, and particularly, of stimulating department managers to generate it. It is not the concern for generating value, but that of enforcing a financial control, as strict as possible, that encourages costs diminution and activity restraint for the detriment of investments and growth. Excessive control leads to value destruction for stakeholders and clients, and eventually, as the company loses its competitiveness, for the employees. The design and the analysis of a system of performance indices, meant to achieve a balance between managerial control and operational risk assumption, may appear as a fundamental, but, at the same time, fragile, condition for success. It cannot be confused with the aggregate of control.

iv. Communication and Information System. The information flow is essential for a control system (Adam, Ebert, 2001, p. 437). Among the components of the informational system specific to an organization, the accounting information subsystem plays the most important role in planning and controlling the economic activity of the organization, being the most developed information subsystem of the company, due to the high volume of accounting information. Therefore, field literature points out the fact that $80 \%$ of the information spread within the systems of an organization is of economic nature, and $47 \%$ of this economic information is of accounting nature 
(Oprea et. al., 2002, p. 334).... But this does not give us the right to reduce control and/or control function of the management to the stage of financial and accounting verification.

Considering the process of control, we estimate that the communication system transcends the informational one. Blind informatization in excess based on attendants' mystification, illusion of transparency, informational full intensity may engender uncontrollable and delayed effects. "Information is highly probable to become a kind of unexploded bomb, in the sense that information has no longer the deliverable effect, and not only it becomes useless in solving the issues, but may generate new ones, recurring to pseudo-information - information lacking addresses and significance" (J. J. von Cuilenburg, O. Scolten, G. W. Noomen, 1998 in Zlate, 2004). Under these circumstances, an efficient organizational communication becomes necessary in order to settle responsibilities, to precisely limit authority and tasks, to provide an optimum control.

v. Supervision or Internal Audit. Supervising activities refer to permanent or periodic evaluation of control functioning quality performed by the management of an organization in order to determine whether its mechanisms are applied according to enforced regulations and whether they are modified accordingly when dealing with changes of circumstances.

The most important aspects of the monitoring activity are determined by the main types of supervising activities developed within a company and by the way in which these activities influence control mechanisms, whenever it is the case.

We also mention that the size of an organization determines a significant impact over the nature of control and over specific control mechanisms applied during the activity. Therefore, developed and high developed organizations counts on highly formalized, impersonal, controls with feed-back, while, and less developed organization are rather controlled in an empirical manner, abiding the principles and other elements mentioned before.

\section{Conclusions}

We consider that the utterances presented in this paper, as well as several elements encountered in the field literature and in daily experiences, provides us a basis for reporting verification-evaluation to the control function of the management. Therefore, synoptically reducing the concept of control to the surface and the shape of a circle (figure 3), we may state that, considering a plastic point of view, the lines plotted on the graph represent the part consisting of evaluation-verification (verification and internal audit activities) of the whole, here, the control function of management. Intersections of the lines, for example, may stand for real redoubt of fight against the risks etc.

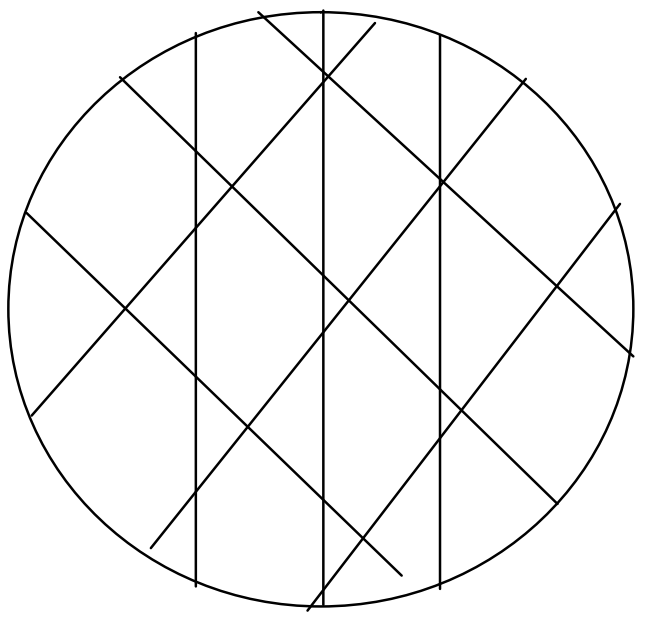

Fig. no. 3 - Correlation between the whole, namely, control and a certain part, namely, verification-evaluation 
Adopting this vision, we consider that a more concerned use of concepts of: control, controlevaluation, evaluation, audit, verification-evaluation, verification etc, is needed. When speaking of control, the audit and verification may be involved, but they do not represent the same meanings and it is highly recommended not to confuse the language used.

Control is an attribute of a more ample management, which includes a certain way of designing, achieving and working of systems and relations. As mentioned before, beside verification and audit, control also includes: leading philosophy and attitude, level of education, training and morality of employees etc.

Consequently, we suggest applying the sense of order and conformity inquiry for verification and that of dominance, interception and "leading" of a certain process, of an activity or/and of an entity, for control. The concepts of verification and audit correlated to that of control define the relation between parts and the whole. A better evolution of the first two concepts within an organization generates grater chances of achieving an adequate control, but we need much more in order to exhaustively introduce the concept of control function of the management. Moreover, as verification, audit and evaluation get weaker within the aggregate of control, without affecting goals achievement process, the reference system or organization becomes more performant.

\section{References}

1. Adam Jr. E. E., Ebert R. J., 2001, Managementul producției şi al operaţiunilor, Teora, Bucureşti.

2. Anthony R. N., 2001, Management Control Systems, McGraw-Hill.

3. Anthony, A.N., 1995, Govindarajan, V., Management Control Systems, Chicago: Irwin.

4. Arens A. A. et. al.., 2006, Audit - o abordare integrată, Ed. ARC, Chişinău.

5. Beatty J., 1998, Lumea în viziunea lui Peter Drucker, Teora, Bucureşti.

6. Boboc I., 2003, Comportament organizaţional, Ed. Economică, Bucureşti.

7. Burlaud A., Simon C. J., 1999, Controlul de gestiune, Ed. C.N.I. Coresi, Bucureşti.

8. Certo S. C., 2002, Managementul modern, Teora, Bucureşti.

9. Cristea M., Can Insurance Company Control their Financial Stability? Practical Solutions, MPRA Paper, No. 10067, Aug. 2008, University Library of Munich, Germany, http://mpra.ub.unimuenchen.de/10067/.

10. Dalotă M. D., 2003, Management, Ed. Orizonturi Universitare, Timişoara.

11. Görg B., 1997, Managerii viitorului. viitorul managerilor., Ed. Institutul European, Iaşi.

12. Harrington H. J., Harrington J. S., 2000, Management total în firma secolului 21, Teora, Bucureşti.

13. Hesselbein F., Goldsmith M., Beckhard R., 2002, Organizația viitorului, Editura Teora, Bucureşti.

14. Huțu C. A., 2003, Cultură. Schimbare. Competiție., Ed. Economică, Bucureşti.

15. Ionescu Gh. Gh., Cazan E., 2004, Management, Ed. Universităţii de Vest, Timişoara.

16. Ionescu Gh. Gh., 2005, Marketizarea, democratizarea şi etica afacerilor, Ed. Economică, Bucureşti.

17. Morris M. H., Noel T., Schindehutte M., Entrepreneurship and Need for Management Control: Efficiency versus Effectiveness, http://usasbe.org/knowledge/proceedings/ proceedingsDocs/USASBE2001proceedings-054.PDF.

18. Năstase M., 2004, Cultura organizaţională şi managerială, Ed. A.S.E., Bucureşti.

19. Nicolescu Ov. (coord.), 2003, Sistemul organizatoric al firmei, Ed. Economică, Bucureşti.

20. Nicolescu Ov., Verboncu I.,2001, Fundamentele managementului organizației, Ed. Tribuna Economică, Bucureşti.

21. Oprea D., Airinei D., Fotache M., 2002, Sisteme informaționale pentru afaceri, Polirom, Iaşi.

22. Russu C., 1999, Management strategic, Ed. All Beck, Bucureşti. 
23. Spira L. F., The Reinvention of Internal control and the Changing Role of Internal Audit, www.emeraldinsight.com.

24. Stanciu Şt., Ionescu M. A., 2005, Cultură şi comportament organizaţional, Ed. comunicare.ro, Bucureşti.

25. Tannebaum A.S., Control in Organizations, 1968 in Lowe, T. and Machin, L.J., New Perspectives in Management Control, London: The Macmillan Press Ltd, 1988.

26. Ulrich D., 2002, Organizarea în jurul capacitaților, in în Organizația viitorului, Teora, Bucureşti.

27. Vries M. K., 2003, Leadership, Ed. Codecs, Bucureşti.

28. Zlate M., 2004, Tratat de psihologie organizațional-managerială, Polirom, Iaşi.

29. O. G. nr. 119/1999 concerning public internal control and preventive financial control, republished in the Official Jurnal of Romania no 799, of November 12, 2003.

30. Romanian Language Explicative Dictionary, Ed. Academiei, Bucureşti, 1998.

31. Turnbull, 1991, Internal Control Working Party. 